This is the peer reviewed author's version of the following article: Chen, J. C. (2019).

Restorying a "newbie” teacher's 3D virtual teaching trajectory, resilience and professional development through action research: A narrative case study. TESOL Quarterly. Advance online publication. https://doi.org/10.1002/tesq.550 . 


\title{
Restorying a "newbie" teacher's 3D virtual teaching trajectory, resilience and professional development through action research: A narrative case study
}

\author{
Abstract \\ Unique affordances of 3D multi-user virtual environments (MUVEs)—e.g., immersive \\ simulation, avatar tele/copresence - have attracted language teachers/researchers to explore \\ the effects of Second Life (SL) on learners' language outcomes and perceptions. Research on \\ such a synergy of language education and virtual learning has suggested learners' heightened \\ motivation, improved communication skills, boosted confidence, and developed avatar \\ identity. Nevertheless, the target population in prior research is predominately language \\ learners whereas teachers' professional development and beliefs in 3D virtual teaching are \\ relatively under-researched. Motivated by action research, this case study explores how an \\ ESL teacher switched her role from an experienced classroom-based teacher to a SL newbie \\ teacher, thus reconstructing her teacher identity and fostering professional growth. \\ Coinciding with narrative inquiry, her verbatim account was documented in her critical \\ reflections in blogging, shadowed and interviewed by the researcher as her mentor. Her story \\ epitomises an online teacher's resilience in striving to equip herself with a new skill set and \\ new understandings of online teaching vis-à-vis challenges encountered, strategies employed \\ and lessons learned through critical reflections in dialogue blogging. These aspects open a \\ new avenue for research and pedagogy in virtual teacher training and professional \\ development through action research in the $3 \mathrm{D}$ virtual environment.
}

\section{Introduction}

Multi-user virtual environments (MUVEs) have increased in popularity over the last decade with evolution of 3D gaming. Defined by Wagner and Ip (2009), MUVEs are "immersive, three-dimensional (3-D), multi-media, multi-person simulation environments" (p. 250) that can have either a structured game-play focus, requiring users to complete objectives or missions as seen in games such as World of Warcraft, or a social networking focus allowing users to explore the 3D MUVE for socialising purposes (Wehner, Gump, \& Downey, 2011). One such example is Second Life, created by Linden Lab in (2003) which recorded 36 million user accounts in its $10^{\text {th }}$ year of existence (Linden Lab, 2013). Second Life (SL henceforth) comprises thousands of user-created islands, some of which are realworld replicas of popular cities and tourist destinations and others are fantasy-based realities tailored to a particular theme or interest group. SL users (also called residents in SL) create customised avatars to interact with others and the 3D MUVE, often in ways which are not possible in real life such as flying and teleporting (Kluge \& Riley, 2008). Other dimensions to SL include engaging in commerce with Linden Dollars, for which residents exchange realworld currency and use an "in-game payment mechanism" (Wagner \& Ip, 2009, p. 251) allowing them to purchase lands and building rights for the creation of structures and 3D objects, to pay for virtual food in restaurants and to immerse fully in the SL experience.

Given the unique affordances of 3D MUVEs (e.g., real-world simulation, multimodal communication, immersive collaboration, avatar tele/copresence), language teachers and researchers have started to explore the effects of SL on learners' language outcomes and perspectives. Research on such a synergy of language education and 3D virtual learning has suggested learners' heightened motivation and engagement (Peterson, 2010, 2012, 2016; Wehner, Gump, \& Downey, 2011), improved communication skills (Chen, 2016a, 2018; Deutschmann, Panichi, \& Molka-Danielsen, 2009), boosted confidence level (Chen, 2016b; Lan, Fang, Legault, \& Li, 2015), raised crosscultural awareness (Canto, de Graaff, \& Jauregi, 2014; Jauregi, Canto, de Graaff, Koenraad, \& Moonen, 2011) and developed avatar identity (Deutschmann \& Panichi, 2013; Liang, 2012). Despite the positive claims, language learners 
are predominantly the target population for research as opposed to teachers (Peterson, Wang, $\&$ Mirzaei, 2019). The role of online language teachers in 3D MUVEs, however, is still a less charted territory that deserves more empirical studies to place this agenda on the research map (Compton, 2009; Kozlova \& Priven, 2015). Worth exploring is how language teachers utilise instructional strategies and technological resources to tackle challenges encountered in SL as novices. Equally important is examining how SL newbie teachers' teaching experiences shape and are shaped by their teaching beliefs and new understandings, thus refining their teaching repertoires in online teaching. Action research, hence, provides a relevant framework for both practitioners and researchers to critically reflect on whether context-responsive action plans can bring changes to pressing issues impacting the involved participants while systematically documenting results to make further evidenced-based actions (Burns, 2015, 2016). Specifically, investigating how novice teachers' apprenticeship and supervisors' mentorship play out in an online environment also deserves much needed attention (Sato \& Chen, 2019).

Informed by narrative inquiry (Barkhuizen, 2015), this case study reports on an English language teacher's journey of her first virtual teaching in SL, illustrated by her critical teaching reflections in blogging, shadowed and interviewed by the researcher as her mentor in an online supervision fashion. Implications drawn from her unique story also shed light on research and pedagogy in teacher professional development and virtual mentorship in online language teaching through action research.

\section{Literature Review}

\section{Language Teachers in SL}

Though not originally launched for educational purposes, SL has attracted a growing number of educational institutions to start building 3D campuses, offering online courses and holding virtual conferences in this 3D sphere (Kluge \& Riley, 2008). SL enables universities to grow their distance and online education programs across a wide range of education disciplines (Gregory et al., 2013; O’Connor, 2009; Stevens \& Stevens, 2012), such as Management Information Systems (Wagner \& Ip, 2009), Mathematics and Information (De Lucia, Francese, Passero, \& Tortora, 2009), Business Writing (Remley, 2010), English Oral Production (Petrakou, 2010), Computer Science (Barker, 2011) and within Art History and Business subjects (Stevens \& Stevens, 2012). It is also found that SL affords several benefits for students when learning is situated in this 3D MUVE. Firstly, SL fosters personalised learning experiences (Mon, 2010) due to its highly interactive and learner-entered environment that allows students to create and customise objects (Kluge \& Riley, 2008). Secondly, its immersive nature and similarity to the real world affords students to easily transfer skills learned in SL into a real-world environment (Delgarno \& Lee, 2010). Indeed, Barker (2011) emphasises the importance of designing learning activities in SL that are closely connected to the real world to ensure relevance and usefulness. For example, roleplay, which is commonly used in SL, provides students with immersive simulation into alternate perspectives (Mon, 2010). Next, the highly social nature of SL allows for student collaboration in real time (Delgarno \& Lee, 2010), enabling a deeper level of social interaction than other online asynchronous learning tools (O'Connor, 2009).

Another benefit of SL is that students can "teleport" to expert communities of practice in virtual destinations like university campuses and museums (Mon, 2010). This unique feature affords teachers and students to conduct virtual field trips anytime, anywhere in order to enrich real-world learning experience that may not be available or difficult to realise in a physical class (Dawley \& Dede, 2014). Lastly, the game-based nature of SL appeals to $21^{\text {st }}$ century students, many of whom enjoy using online game environments in their personal lives (De Lucia et al., 2009, p. 221). It has been indicated that virtual environments like SL 
increase student engagement (Kluge \& Riley, 2008) although Dass, Dabbagh and Clark (2011) argue that engagement is not an automatic by-product of conducting a class in a virtual world and that task design in SL should be relevant to students and also within their technical skills. On that note, Petrakou (2010) indicates that tutors should be mindful of how a lack of technical skills may impede a student's ability to interact fully with others in the virtual space. Furthermore, digital platforms like SL and other educational technologies "do not directly cause learning to occur but can afford certain learning tasks that themselves may result in learning" (Delgarno \& Lee, 2010, p. 17).

The pedagogical benefits rendered by SL have also motivated language educators to transform a traditional class setting into one that fosters intercultural competence through interacting with SL residents from different linguistic/cultural backgrounds, exposure to rich input, authentic communication, language skills build-up, and high-order cognitive processing (Canto, Jauregi, \& van den Bergh, 2013; Sadler, 2012). The nature of openness and flexibility makes SL an optimal platform to create more opportunities for real-world task simulation, which could be cumbersome to carry out in a physical class (Dawley \& Dede, 2014; González-Lloret \& Ortega, 2014). Despite those positive claims, technical glitches encountered in SL have also been reported, such as platform instability, poor quality of audio output and echoing, higher hardware demand, and internet connection interruption (Chen, 2016a, 2016b; Dawley \& Dede, 2014; Kozlova \& Priven, 2015; Petrakou, 2010; Peterson, 2010). These caveats need to be taken into account in order to pre-empt SL malfunctions that may backfire on well-planned lessons and students' learning experiences.

Notably, prior studies are geared more towards learner-based research, targeting SL as a potential language learning environment (Chen, 2016a, 2016b, 2018; Canto, de Graaff, \& Jauregi, 2014; Deutschmann \& Panichi, 2013; Peterson, 2010, 2012; Lan et al., 2015). Research focusing on the impact of 3D virtual teaching on language teachers' professional development and beliefs is relatively scarce. This disproportionate trend mirrors the inference drawn in Compton's (2009) comprehensive literature review, concluding that "little has been done to prepare language teachers for online language teaching" (p. 92). This observation is also echoed by Kozlova and Priven (2015) that "...little is known about the knowledge and skills teachers need to acquire to provide effective task-based instruction in 3D [MUVE] and the type of teacher training that best prepares instructors for such an endeavour" (p. 84). Indeed, teaching in a 3D virtual world is not simply cloning an in-class syllabus by default, but requires higher demands of technological skills and time in creating a MUVE-enabled, pedagogically-feasible class (Kluge \& Riley, 2008). For example, Cheong's (2010) study discovers that pre-service Korean teachers were able to hone their teaching skills through ongoing collaborative teaching in avatar-enabled practicum in SL, leading to their stronger sense of teaching efficacy. Nevertheless, other technical and instructional issues also need to be ironed out, such as the comparability of transferring lecture materials and assessment tasks into SL, the ease of managing a virtual class, communication channels, virtual community building and on-site support safeguarding novice teachers from grappling with technical glitches (Lin, Wang, Grant, Chien, \& Lan, 2014).

\section{Action Research in the Virtual World}

Action research involves a self-reflective, systematic and critical approach to enquiry by participants who are at the same time members of the research community. The aim is to identify problematic situations or issues considered by the participants to be 
worthy of investigation in order to bring about critically informed changes in practice. (Burns, cited in Cornwell, 1999, p. 5)

The definition offered by Anne Burns above cogently captures the essence of action research (AR hereafter) and the significance of conducting AR in the fields of TESOL and language education. As AR entails, one of the pivotal elements in AR is to problematise the status quo (e.g., a grammar-based syllabus or high-stakes testing) and bridge the gap between what is not working and what is desired by the impacted stakeholders, such as students, teachers, administrators (Burns, 2015). Given the applied and practitioner orientation, this contextresponsive approach rings true to most language teachers as it champions the teacher-asresearcher ecology to address a local classroom or school-wide issue while heralding collaboration between teachers and researchers (Creswell, 2012; Edwards \& Burns, 2016). It gives voice back to teachers and enables them to improve their day-to-day practices, thereby empowering teacher identity, fostering self-agency, and promoting professional development (Alwright \& Bailey, 1991; Goodnough, 2010, Yuan \& Burns, 2017). Other commonly used terms related to AR are practitioner inquiry/research, teacher research, participatory action research, critical action research, and cooperative inquiry/research (Burns, 2015).

Teacher practitioners play a crucial role in AR as they are both participants (who initiate and drive action) and researchers (who investigate the phenomenon in order to resolve the burning issue) (Burns, 2015). The research dimension encompasses an ongoing process of "planning (or identifying an issue), acting (conducting some kind of intervention related to the issue), observing (collecting forms of evidence), and reflecting (analysing the evidence and reflecting on the intervention experiences)" (Burns, 2016, p. 57). This dynamic AR process iterated in stages of planning, acting, observing, reflecting (Kemmis \& McTaggart, 1988) enables teacher researchers to probe into the identified areas, act on the contextresponsive plans, systematically gather data-driven evidence, and above all, critically observe and evaluate the outcomes before taking further actions or disseminating the findings (Burns, 2015, 2016). The ultimate goal is to bring positive changes to the current situation concerning the participants, generate research-oriented, pedagogically-sound knowledge, and engage teachers to team up with researchers (Creswell, 2012). Consequently, AR promotes ongoing teacher professional development that further transforms teacher identity and self-efficacy (Edwards \& Burns, 2016; Goodnough, 2010; Yuan \& Burns, 2017). Hence, AR opens up an ecological venue for both language educators and researchers to address and solve immediate problems from within.

AR is generally associated with classroom-based research as the mainstream course delivery typically resides in a physical classroom setting (Alwright \& Bailey, 1991; Burns, 2015, 2016; Creswell, 2012). Prior AR studies are mostly conducted in ESL or EFL classes and address issues related to the development of teacher identity, agency and professional growth (Edwards \& Burns, 2016; Goodnough, 2010; Yuan \& Burns, 2017) or the impact of AR on language learners' language outcomes, motivation and curriculum design (Banegas, Pavese, Velázquez, \& Vélez, 2013; Sowa, 2009). Although positive findings suggest the primacy of empowering classroom teachers through AR, research geared towards online ESOL teachers or situated in a fully online context is relatively under-researched (see Rovegno \& Pintos, 2017, for online EFL teacher professional development through AR). This research gap is even wider in the context of SL as little is known about how AR impacts SL newbie teachers' 3D virtual teaching practices, teacher identity and professional growth. Similarly, the extent to which AR can translate into online teacher training through virtual mentoring and collaboration with researchers is also less explored.

As indicated above, hurdles such as virtual class management, technical issues, content delivery, task execution and modification, timely feedback, and student performance 
evaluation, are challenging newbie teachers in SL (Kozlova \& Priven, 2015). Critically reflecting on their teaching practices and ideally having a mentor to supervise them throughout the teaching journey is integral to newbie teachers' professional development in a virtual environment (Sato \& Chen, 2019). This urgent concern, hence, propels this study to document an English teacher's first virtual teaching trajectory and unfold new dimensions in teacher resilience, reshaped identity and virtual mentorship through AR in SL.

\section{Methodology: Narrative Case Study}

Exploratory in nature, this study examines how a classroom teacher switched her role to a SL newbie teacher in her first online teaching. Noteworthy is how she strove to equip herself with a new skill set and to reconstruct her teacher identity in SL. Given that the SL newbie teacher is "the case" of interest, a case study research design was employed to explore this target phenomenon. According to Duff (2012), one of the case study strengths is to exemplify a contextual phenomenon in a more illuminating, personalised and concrete manner, thus offering insightful understandings of the nuanced patterns in a case under investigation. Through the lens of her virtual teaching journey, the new understandings developed in online teaching regarding challenges encountered, strategies employed, lessons learned and reflections exchanged, add research and pedagogical insights to the current literature that is still lacking empirical studies in this regard.

In tandem with the essence of a case study, a narrative inquiry approach was also adopted as "a way of doing research that focuses on the stories we tell about our lives...the meaning we make of the events we live or imagine in our future lives" (Barkhuizen, 2015, p. 169). As such when a participant tells an audience about his/her life experiences, those experiences turn into narratives as part of inquiry for research purposes and vicariously transport the readers to the real-life history that renders transferability. Narrative inquiry also allows teachers/learners to get their voices heard (thus empowered) and enables readers to understand how they make sense of their teaching/learning experiences (Barkhuizen, 2015). Finally, the synergy of narrative inquiry and case study coincides well with the research methodology adopted in AR that values "personalization, subjectivity and localization" (Burns, 2016, p. 57).

\section{Meet Sabrina: The SL Newbie and her Class}

Having earned a graduate diploma in Secondary Education (specialising in English as an additional language/dialect) and a Master of Education degree by research, Sabrina ${ }^{1}$ has been an English lecturer at the college level since 2011. The study was conducted at a Western Australian college where she teaches international students communication skills and academic writing in a remedial English Support Program (ESP) of the college. The ESP program aims to assist those struggling students who fail to meet the entry level of English proficiency and generally receive IELTS scores of 5 or below. Therefore, these at-risk students require additional academic and language support in improving their English oral and written skills in order to cope with academic demands before transitioning into regular university-level courses.

Despite the well-intentioned ESP, Sabrina observed that ESP students tend to find the program boring as its syllabus focuses heavily on grammatical structures and academic writing styles. Oral communication skills, albeit addressed, are embedded in more serious oral presentations as "many [students would] sit in the class and participate minimally and $\mathrm{d}[\mathrm{id}]$ not enjoy the oral presentation type activities" (Sabrina, interview, 17/12/2016). The mismatch between the nature of ESP and the learning interests of the students resulted in

\footnotetext{
${ }^{1}$ A pseudonym was created for the participant in order to protect her real-life identity.
} 
their disengagement and diverted attention to Facebooking or texting. This urgent concern witnessed by Sabrina motivated her to find solutions to transform the ESP program and better serve those low-proficient students. The idea of establishing an online version of ESP to provide more opportunities for meaningful, communicative and authentic practices was then formed. She discussed with the researcher the feasibility of teaching an online ESP and was informed of the utilisation of SL as a platform for English teaching and learning. Despite her unfamiliarity with online teaching, much less a 3D virtual environment, she saw the potential of this innovative approach that might benefit student learning motivation and outcomes. She proposed the plan to the ESP Director and gained her full support to implement this new approach in the upcoming term.

Sabrina's case vividly exemplifies how AR can be triggered by teachers' critical observation of identifying a problematic situation in their every practices and exploring viable plans to resolve the issue (Burns, 2015, 2016; Creswell, 2012). The following delineates how her action plan, guided by the researcher as her mentor, was executed and evidenced in systematic data collection and analysis. A visual representation of the ongoing, systematic AR process is also presented.

\section{Action Plan: Teacher Training and Syllabus Design in SL}

To comply with the college's mandatory policies, the proposed online ESP equally ran two hours per week over a seven-week term as the traditional ESP. What set the online ESP apart from its counterpart was that Sabrina conducted each online session in a computer $\mathrm{lab}^{2}$ where students could access intranet-wired PCs to perform assigned tasks in SL. Both Sabrina and the students used their avatars to interact with each other using mostly voice chat (configured by headsets) to carry out SL tasks, and text chat to clarify meaning if need be. A class website was also created for students to practice writing by responding to lesson-related prompts after each session. All participants were informed of the purpose of this study ${ }^{3}$ and that this online ESP was an alternative to their regular ESP and lesson tutorials would be carried out in SL. This student cohort had never taken an online course previously and showed great interest in improving their spoken and written communication skills in the 3D virtual world. They are all young adult learners aged 18 to 30 and speak Chinese, Cantonese, Arabic, Mandingo, and Urdu as their L1s. Their informed consent was gathered before the study started.

Guided by the researcher, Sabrina started a series of teacher training sessions on how to facilitate the task delivery in the virtual class. She first created her avatar on SL's Welcome Island and practiced key functions such as teleporting, flying, changing outfits, setting landmarks, using voice/text chats, sending notecards and building 3D objects. Given the unique affordances in SL, she consulted with the researcher to develop a SL-enabled, taskbased syllabus to enhance learning for authentic and communicative purposes. To illustrate, students were to simulate real-life (RL) tasks (e.g., dining at a 3D restaurant), teleport to a gallery and describe an artwork of interest, interview a SL resident and debrief the information, help a peer build a 3D object and exit a maze following notecard instructions, and change the avatar outfit to showcase their cultural clothing.

Enhanced by SL, these pedagogically-sound tasks were also operationalised under the methodological principles of task-based language teaching (TBLT), such as learning by doing, negotiation of meaning, collaboration, authenticity, problem-solving and exposure to

\footnotetext{
${ }^{2}$ Given the technical demands and the fact that some students didn't have personal laptops, a computer lab was utilised so that all the students could carry out SL tasks in ESP Online. ${ }^{3}$ Findings on ESP students' experiences and perspectives of the online ESP were reported elsewhere.
} 
rich input (Doughty \& Long, 2003; González-Lloret \& Ortega, 2014; Ortega \& GonzálezLloret, 2015). All the lecture sessions were videorecorded and uploaded to ESP's YouTube channel for teaching and research purposes. A full version of the task-based syllabus can be accessed via https://goo.gl/KgRM2w. Figures 1 and 2 exemplify two SL tasks respectively: restaurant dining role-play (session 3 ) and object building (session 4).

\section{(insert Figure 1 here)}

\section{(insert Figure 2 here)}

\section{Retrospective Data}

PBworks (http://www.pbworks.com/), a free wiki site for file sharing and collaboration, was chosen as an open space for Sabrina to document her teaching journey in SL. She posted her reflections of her teaching performance and critically evaluated student reactions to SL tasks right after each session. Video-recorded sessions on moment-to-moment activities (as shown in Figures 1 and 2) were utilised as evidence-based sources to prompt her reflections. To ensure that Sabrina was well supported as a newbie teacher, the researcher also provided guidance in response to her concerns and thoughts in her blogging (Figure 3). To corroborate dialogue blogging with Sabrina, the researcher also conducted a semistructured interview with her (see Appendix) at the end of ESP Online.

Qualitative data drawn from Sabrina's dialogue blogging and oral interview in this single case study also lent itself to narrative inquiry. As Barkhuizen (2015) argues, "[n]arrative research methods are also aligned with other types of qualitative methods, such as oral interviews, diaries, or blogs...[it] requires the individual's commitment to the construction of meaning-making stories that encompass his/her lived experiences in particular spatiotemporal contexts" (p. 171). The ongoing commitment made by her to blogging and dialoguing with the researcher also alleviated the pitfall of the burden typically placed upon participants in narrative research. In the same vein, the narrative genre also resonates more with likeminded teachers who are interested in the stories of how other practitioners tackle practical issues and collaborate with researchers in AR (Burns, 2016).

\section{(insert Figure 3 here)}

Taken together, the researcher as Sabrina's mentor was able to observe and shadow her moment-to-moment SL teaching via video-recorded sessions and offered guided supervision throughout the two-way dialogue blogging (Sato \& Chen, 2019). This ongoing and systematic approach closely reflected the nature of active engagement, critical reflection, context-responsive mentoring, and teacher-researcher collaboration in AR (Creswell, 2012). To better illustrate how AR was operationalised in Sabina's case, the classic AR model proposed by Kemmis and McTaggart (1988) was adopted. Figure 4 presents the four key stages in planning, acting, observing and reflecting, as well as the corresponding actions taken in each stage.

\section{(insert Figure 4 here)}

\section{Data Analysis}

To reiterate, this AR approach marries a case study research design with a narrative inquiry approach (Burns, 2016) in order to paint a fuller picture of a newbie teacher's online teaching practices in SL. A case study seeks depth rather than breadth and can yield particular insights applicable to wider theoretical significance and relevance rather than 
universal generalisation (Duff, 2012). In our case, narrative inquiry through dialogue blogging and the interview enables the researcher to examine how Sabrina positioned herself in her teaching trajectory, acquired new knowledge, constructed teacher identity, interacted with students and executed tasks in the investigated phenomenon (Barkhuizen, 2015). Given the socially constructed nature of the narrative data, the researcher employed content analysis to restory Sabrina's teaching journal by recursively perusing data sources for salient patterns, associating recurring patterns with related themes before reaching at a higher conceptual level (Friedman, 2012).

After weaving through Sabrina's meaning making process in SL teaching, the researcher reconstructed themes from the data into a coherent storyline (Barkhuizen, 2015). It not only gave voice back to her in telling and sharing her story, but rendered empowerment through her critical reflection and evaluation of her first online teaching — an integral part of AR (Edwards \& Burns, 2016; Goodnough, 2010; Yuan \& Burns, 2017). To address "trustworthiness" in qualitative research, rich description was evident in a full account of her SL teaching experience; member checking with Sabrina was sought to ensure the thematic categories and initial findings were accurately interpreted; in-vivo codes (Sabrina' verbatim) were used as evidence to highlight salient findings; and transferability was maximised by vicariously transporting the readers to her teaching trajectory in SL as if they were with her throughout her SL journey (Merriam \& Tisdell, 2016).

\section{Results and Discussions}

\section{Teaching in SL: A Rollercoaster Ride}

As reported in prior studies, technical issues are not uncommon in SL teaching (Chen, 2016a, 2016b; Dawley \& Dede, 2014; Petrakou, 2010; Peterson, 2010) and were also encountered in this study. Although conducting SL sessions in a lab setting (as in this study) provides more stable bandwidth to accommodate a higher demand of 3D graphics, "voice quality, headset issues" can still interrupt the lesson flow, virtual class management and task delivery and "it requires a lot of time, training for the teacher and students and technical know-how" (Sabrina, interview, 17/12/2016). It also becomes a double-edged sword backfiring on the essence of SL, which is more "natural" when members are remote from each other. As such, the fact that all the students and teacher were physically present in the lab not only amplified the technical difficulties (e.g., echo in the room when multiple speakers were talking in SL), but counteracted SL affordances realised in distance learning. Sabrina critically examined this aspect in her interview,

I think running this class in a computer lab held all of us back - for myself, it held me back from fully adopting an online/ virtual teaching style (I was constantly torn between the virtual and physical settings). For students, having me in the room, meant that they never fully owned their virtual experience and by implication, their language learning... Remove the safety of the physical classroom [students and myself] would've had no choice but to utilize the avatar to the full extent.

Though experienced in classroom-based teaching, Sabrina's debut online teaching as a SL newbie reveals insightful aspects for pedagogy and research. She witnessed the instructional "potential" SL could bring to transform a teacher-centred ESP class (focusing more on grammar and academic writing) into an exhilarating learner-centred playground (geared more towards authentic task communication). Specifically, her observation of the levels of increased student engagement and motivation validated her positive perception about the effects of 3D virtual teaching on student learning outcomes. She recounted in her interview (17/12/2016) the marked difference in teaching in SL versus a traditional ESP, pinpointing the observable progress in oral performance of students who tended to be reticent but started to open up using voice chat, 
Overall, SL has huge potential for language learning classrooms. It has the ability to capture student attention and package language learning in a new and exciting way compared to RL teaching which many language students are bored with... Seeing the engagement levels of students increase within a language learning context. Seeing even the most shy and reserved students, even those with the weakest English speaking skills, open their mouths and share their thoughts within the given SL task. This noticeable learning evidence didn't happen in a vacuum. Unique SL features are linked to those positive claims as reported in prior studies, such as an open space for playing creativity in learning (Kluge \& Riley, 2008; Dawley \& Dede, 2014), real-time communication (Deutschmann et al., 2009; Deutschmann \& Panichi, 2013; Jauregi et al., 2011; Wehner et al., 2011), avatar-enhanced tele/copresence in community building (Sadler, 2012) and immersive simulation in 3D form (Peterson, 2016; Peterson et al., 2019). In Sabrina's case, the multimodal tools (Chen, 2016b, 2018) realised in text chat "increased writing output" and speaking via avatar "gave students anonymity and confidence to speak in English more so than in a face-to-face language class" (Sabrina, interview, 17/12/2016).

While it was rewarding to see her students motivated and willing to communicate out of their comfort zone, the mixed feelings about having the teacher control removed also indicates the shift in her teacher identity from a classroom teacher to a SL teacher. As she candidly remarked in her interview (17/12/2016),

The reduced amount of control that you have as a teacher ... Not being able to (or trying hard not to) get up and go over to each student and check how they were doing, but rely instead on SL Chat/Voice, made me feel disempowered. It was hard to let go and give the students the control, to own their own experiences. Hard for me, but perhaps better for them?!

This dilemma exemplifies how teaching in SL had problematised Sabrina's classroom-based teaching philosophy. As SL is a free, open venue that signals expect the unexpected in instruction, her mindset about "teachers should be in control or would be disempowered" (Sabrina, interview, 17/12/2016) had been challenged in the context of 3D virtual teaching. The new understanding that she needed to wear a new online teacher's hat rather than clinging to her classroom teaching mindset reshaped her teacher identity.

This finding implicates the crux of pedagogical ecology in online teaching vis-à-vis the unpredictability in the 3D virtual world (Chen, 2018). While allowing students to access SL remotely outside the class might sound daunting or even "messy", it could "push" both the teacher and students to be more immersed in SL, thereby using SL features to the fullest. To fully embrace online teaching (as opposed to a "hybrid" mode) could mitigate technical disturbances such as microphone echoing in a close SL vicinity or student overdependence on teacher's physical presence.

\section{Task-based instruction in SL: A breeze of fresh air?}

As we recall, this task-based, SL-configured ESP Online was as new to Sabrina as it was to the students. Each SL session followed a carefully planned task-based lesson (see the online syllabus), capitalising on the related SL features in order to facilitate task delivery. Traditionally, regular ESP focuses more on academic writing and grammar whereas oral skills are only dealt with in formal oral presentations. Given the lower proficiency of the students (IELTS scores at 5 or below), tasks that required them to use English spontaneously in task-based interaction (e.g., guiding a peer to exit the maze or interviewing an avatar stranger) seemed challenging to them. The demands of task process and authentic communication (as opposed to scripted oral presentations in class) also led to Sabrina's initial qualms about the effectiveness of this new approach. Unexpectedly, seeing them take the reins of their task-based learning in SL reinvigorated her online teaching to some extent, 
evidenced in "Many students described ESP Online as being more exciting, interesting, fun, motivating and I could clearly see the benefit for their speaking skills and increased confidence in practicing the target language" (Sabrina, interview, 17/12/2016).

Equally important is the evaluation of specific task effects on student learning outcomes as it is conducive to teacher professional development. When reflecting on the actual task delivery and completion, Sabrina noted the pros and cons of task design in relation to student reactions. Firstly, the most recursive pattern in her observation was the "fun and enjoyment" factor in that "students were very engaged with the gallery... [and] enjoyed listening to each others' descriptions (session two)", "This was a fun task and giving and clarifying directions produced a lot of speaking (session four)", or "Students really enjoyed this one [outfit and runway show] (session six and seven)" (Sabrina, interview, 17/12/2016). Indeed, prior task-based research in SL has suggested the pedagogical benefits of this dynamic synergy that enhance unrehearsed language output (Chen, 2016a, 2018; Canto, Jauregi, \& van den Bergh, 2013; Deutschmann, Panichi, \& Molka-Danielsen, 2009; Sadler, 2012) and bring fun to learning (Chen, 2016b), thereby boosting learner motivation and confidence (Peterson, 2010, 2012, 2016; Wehner, Gump, \& Downey, 2011). Consequently, students in this ESP class felt liberated from the prior ESP experience- English learning in the virtual world could be as fun and engaging as it went. Therefore, this new approach transformed a mundane ESP class and infused fun in English learning.

Nevertheless, she also evaluated the downsides of this task-based approach that got hindered by SL technicality, echoing the caveats reported in prior SL research (Chen, 2016b; Dawley \& Dede, 2014; Kozlova \& Priven, 2015). Technical issues hindered the flow and execution of task delivery, such as difficulty in finding a suitable SL venue in session three, restaurant roleplay ("Our holodeck pizzeria on Virtlantis would not allow voice chat. The location we ended up in was too cramped... Oral production was still high for most students but others were just confused by all the noise/voices and kept quiet") or the mastery of SL skills in session four, object building ("Students' SL skills needed to be stronger to complete this activity more successfully. The complexity of object building menus meant that there was quite a bit of confusion") (Sabrina, interview). These issues indicate the primacy of balancing the levels of SL skills required in tasks and students' responsibility and command of technical skills so that they can stay on task without lagging behind (Dass et al., 2011; Petrakou, 2010). Besides the technical aspects negatively impacting the task delivery, Sabrina also pinpointed the urgent need of this ESP cohort that might not have been fully addressed in this new ESP Online:

...what was lacking was enforcement of English grammar and help with English writing which is a significant weakness for most of this cohort. So I think all the SL tasks were beneficial for students oral language production, encouraged written output for communication purposes but did not meet the need for support with academic English, grammar and language construction. (Sabrina, interview, 17/12/2016) This critical evaluation echoes the commonly held concern by classroom teachers who like to adopt TBLT in their contexts but are suspicious about its effectiveness in improving students' grammatical competence, particularly targeted in EFL settings (Ellis, 2009). Although she did witness students' heightened levels of task engagement, motivation and noticeable oral production, Sabrina felt that grammar teaching and academic writing shouldn't have been played down. Evidently, her teaching beliefs were still influenced by her prior ESP teaching philosophy since these students need to master the required academic English skills in order to succeed in mainstream courses. Her criticism that "... if students could communicate their views in 'broken' English with non-standard grammar, they were succeeding in the task" (Sabrina, interview, 17/12/2016) is also shared by other ESL/EFL teachers questioning the link between TBLT and grammar. The strong version of TBLT (Long, 2016) is challenged 
here and needs to address the context-specific needs of stakeholders, such as students, teachers, and program directors, as they may hold different views about which language aspects should be the centre of attention.

\section{Professional development and virtual mentoring in SL: The AR approach}

The idea of teaching in a 3D virtual environment was never something I imagined myself doing. Online teaching I've thought about, felt a bit anxious about (the differences, not being in the same room as my students or only viewing them via webcam) but teaching as a game-based avatar, interacting with other avatars who are actually real students? What a crazy thought. But here I am, preparing myself to do just that... I find myself involved in a project that requires me to learn new skills and push my own boundaries of what I feel comfortable with...so we'll see how it goes. (Sabrina, blog post, 15/08/2016)

Sabrina's first blog post vividly captures her aspiration for and apprehension of charting new territory in online teaching beyond her comfort zone. Her teaching practice in each SL session was fully documented in her reflective blogging for a four-month duration, starting from the ESP Online preparation (15/08/2016) to the final SL session (16/12/2016). Specifically, the dialogue blogging (see Figure 3) between the mentor (researcher) and mentee (Sabrina) further stimulated more reflections and debriefing in her 3D virtual teaching. This vibrant approach reflects the essence of AR: practitioners' evidence-based observations and critical reflections of the action plan outcomes before further informed decisions could be made (Burns, 2016). It also enables the mentor to provide ongoing, systematic supervision to address the mentee's inquiries and offer context-specific guidance to improve the lessons (Sato \& Chen, 2019). Salient patterns emerging from the dialogue blogging are presented and discussed below.

In navigation of task-based, SL-enabled teaching, Sabrina's resilience and perseverance propelled her through virtual teaching demands and hurdles. To acquire SL skills needed for ESP Online (i.e., planning in AR), she documented how she trained as a newbie, learned SL functions from scratch, experienced initial frustrations with the technicality and gained confidence in mastering those functions as in "Now that I'm feeling a bit more confident with my [SL] skills - not getting lost as much as before... my focus is now on...Using [SL] as a teaching tool!" (Sabrina, blog post, 24/08/2016). In her exploration of creating her own avatar for the first time, she reflected on how the process overwhelmed and challenged her original view about teaching in SL vs. real life and how her avatar persona might be perceived by the students:

The first task I'd set myself was to change my outfit on my avatar. I'd initially chosen a female avatar with short hair like my own...Even in a virtual world, I'm already thinking about the impression I will give off to students... What I thought [outfit changing] would be a fairly straightforward process turned out to frustrate me no end. It was only after I had layered about six new pieces of clothing onto my already dressed avatar that I realised I had to take off existing clothes first! Haha. So this is more like real life than I thought! (Sabrina, blog post, 15/08/2016)

This "a-ha moment" made her more cognizant of the demands in 3D virtual teaching while feeling exhilarated by discovering and mastering SL skills down the track. It also mirrors the crux of orienting teachers to SL features and the sense of confidence building in virtual teaching (Cheong, 2010). The key to successfully implementing TBLT in SL rests with teachers' preparedness of task design "in conjunction with the 3D technology used" (Kozlova $\&$ Priven, 2015, p. 86), which requires well-placed teacher training and ongoing technical support (Lin et al., 2014). As Sabrina stated, "It's been several weeks now of [preparing] for 
our teaching study in Second Life. My technical skills have come on in leaps and bounds, many functions in SL are becoming automatic for me now - progress!" (blog post, 08/09/2016). The sense of achievement further bolstered her teacher self-efficacy in order to embark on more challenging tasks awaiting her.

Interestingly, Sabrina's classroom-based teaching principles continued to evolve and shape her online teaching. Even though she understood that teaching in SL needed to be "flexible", "playing by ear" and "just doing it", her classroom teaching experience still came into play as in "it was more advantageous to meet students face to face [in the lab] before moving fully online and hopefully build some rapport... although previous research has been done without such a luxury" (blog post, 08/09/2016). Not until she started to prepare the restaurant role-play lesson did she realise the technical and instructional demands placed on finding a suitable SL location and testing the compatibility of its features with the task design. As she stated,

One of the most important learning curves...was finding out that not all locations in SL enable voice chat which is a key requirement of our tasks in SL...I spent a good hour teleporting from restaurant to restaurant trying to get our sound working only to finally realise that voice chat was disabled in that particular area...A valuable learning experience! (blog post, 14/09/2016)

Another example is when she finally conducted her first session with the students and soon realised "how the technical side of things took more time than anticipated... and audio testing proved challenging with echo from the sound system in the room" (Sabrina, blog post, 14/09/2016). Indeed, newbie teachers grow as they teach and lessons learned from trial and error can feed into their teaching practices (Kozlova \& Priven, 2015), thus strengthening the action plan as in Sabrina's case (Alwright \& Bailey, 1991; Creswell, 2012; Burns, 2015). Channelling teacher resilience as a coping mechanism is particularly vital since "nothing good comes easy" (Sabrina, blog post, 21/09/2016) for a newbie teacher in SL. What helps them grow is to recoup by fine-tuning teaching and developing context-responsive strategies, thereby fostering a better sense of self-efficacy (Edwards \& Burns, 2016; Goodnough, 2010; Yuan \& Burns, 2017) as mirrored in her following post:

Next week we will begin our actual SL Class Sessions where students will be going solo, just their avatar and the big wide virtual world of SL! Just as my own SL skills have grown and developed over just a few weeks, I'm confident students will get the hang of this quickly, but I anticipate that I will definitely have to draw on [my] own experience as a SL Newbie to guide and encourage our class. (blog post, 14/09/2016) Despite her boosted confidence in SL skills, unexpected technical glitches still thwarted her well-planned lesson preparations. Issues such as "SL being cumbersome", "Wi-fi dropping off", and "echo", all led to the "high levels of frustration" as noted in her blog. While feeling deflated by those inevitable technical difficulties, she also gained new understandings of teaching in SL vs. RL and incorporated them into her next teaching iterations (i.e., acting in $A R)$, as in "...this was even more important in SL so that the student stayed engaged and the pace did not grind to a halt due to technology issues... so many similarities between teaching in RL and [SL], but also noticeable differences!" (blog post, 21/09/2016) or “...I've learned from today [that] teaching in [SL] requires students to take more ownership and responsibility for their learning and [also] requires the teacher to let go and allow things to unfold without the "comforts" of a face-to-face class" (blog post, 11/11/2016).

As ESP Online progressed, she started to reap the fruits of her efforts and commitment put into her SL training and lesson preparations, such as "[s]econd session done with our new cohort - it feels so great to have this under our belts - to finally be getting down to the task-based syllabus and getting a taste of what teaching in SL is actually all about" (blog post, 11/11/2016). This reinforced her teaching belief in incorporating task-based 
design in SL and the potential this dynamic duo could transform a traditional ESP class (González-Lloret \& Ortega, 2014; Jauregi et al., 2011; Peterson, Wang, \& Mirzaei, 2019). Witnessing the positive effects of this synergy on the levels of task engagement and oral outputs demonstrated by the students further validated her implementation of this innovative approach through AR (Banegas, Pavese, Velázquez, \& Vélez, 2013; Sowa, 2009). For example, students needed to identify an artwork that resonated with them in the task of gallery fieldtrip and orally presented it to the class: "Mem24 made me tear up as she described why she was drawn to a painting of a mother and child...students relax and even joke a bit as we listened to each other...lovely feeling... of camaraderie building as a class" (blog post, 11/11/2016). Another highlight was the task of SL restaurant role-play: "The last 45 minutes of the class were wonderful with students engaging with each other, laughing, practicing their English skills and enjoying the task...not everyone stuck to their defined roles [and] just took the conversation where it went...even better!" (blog post, 18/11/2016). Recall that the proficiency level of this ESP cohort was quite low and they tended to be reticent in the regular ESP, which however was not the case in this new ESP Online. This suggests the difference SL-enabled, task-based instruction can make in the oral outputs and motivation of low-proficient learners (Chen, 2016a, 2018; Peterson, 2010, 2012, 2016).

Equally important is the guided mentoring support provided for newbie teachers such as Sabrina during their SL teaching. Challenges encountered in their teaching practices should be evaluated carefully and resolved timely (i.e., observing and reflecting in $A R$ ) especially when qualms tend to arise in the initial stage (Lin et al., 2014; Kozlova \& Priven, 2015). The following episode shows that Sabrina second guessed whether this new approach would work when faced with the unforeseen uncertainties in the planning stage, which were then addressed by her mentor offering a heartfelt reassurance in their dialogue blogging:

Sabrina: I've been putting draft lesson plans together [based] on how I would teach a face-to-face English language class. But is this the correct approach to take? I feel apprehensive...So many unknowns...it is difficult to ascertain if students understand you without being able to gauge body language and being able to read those tangible signs in the room. I imagine it will be as challenging if not more so, in Second Life...Will [students] benefit from what we are trying to do? Will I be able to engage them and enrich their learning experience as I fumble through??" (blog post, 24/08/2016)

Researcher: All the apprehensions are normal and understandable, S., considering it's your first time teaching in SL. It would be insightful to see how those concerns addressed above would go away or still ring true as you progress through the SL teaching journey. I also agree that it's hard to see students' nonverbal cues or facial expressions in SL as you normally do in a RL class...it would be interesting to find out if absence of real-time paralinguistic features would facilitate or debilitate their perceptions about practicing English in SL. A story to be told... (blog post, 24/08/2016)

Indeed, dialogue blogging provides a third space for the mentee to voice concerns and seek advice, and the mentor to track her teaching trajectory and offer ongoing scaffolding. Videorecorded SL sessions also offer evidence-based lessons that help the mentor better observe the moment-to-moment online activities and debrief with the mentee the strengths and weaknesses of that day's lesson (i.e., observing and reflecting in AR), similar to what a supervisor would exercise in a conventional practicum (Alwright \& Bailey, 1991; Burns, 2015, 2016; Creswell, 2012). Online supervision, in this sense, mutually benefited the mentee (newbie teacher) and mentor (researcher) in terms of professional development and teacher training throughout AR (Rovegno \& Pintos, 2017), as in "Thanks for your feedback, it's 
always helpful for me to debrief with you and process the session with someone else!" (Sabrina, blog post, 25/11/2016).

The final scenario showcasing the online mentor-mentee supervision is when Sabrina reflected on her overall experience of her debut teaching in SL. She delineated the ups and downs and some valuable lessons learned in the whole journey, such as providing SL training sessions for students. Her mentor responded timely by first commenting on her lesson delivery of the day and making suggestions about her future teaching in SL:

Sabrina: I must say I felt like I came up for air this week after 5 weeks straight of stressful (but rewarding) sessions in SL. Each week there have been technical issues, students requiring much guidance and hand-holding to help them succeed in the task of the week. And for a teacher it has been full on. I felt so much more relaxed walking around the class from student to student, guiding them as they explored SL for outfits ... It just shows what a learning curve it is for a teacher to shift from face-to-face teaching, to teaching in a virtual environment. Also, number one lesson learned thus far is the importance of technical training for students. An intensive SL skill building program over a few days/week to ensure students can complete tasks independently. (blog post, 15/12/2016)

Researcher: I really liked the way you restructured the lesson that day by striking a balance between working on their reflective writing and the planned SL lesson. I second your point that a precursor to the success of every virtual class is to iron out those technical issues and honing students' tech skills to prepare them transition into the whole online learning format. I also do think that students should also take the reins of all the skills they learn in class and start exploring SL on their own. Part of the reason that they still feel a bit shaky when it comes to more advanced SL technical demands is that they only use SL when they come to the class. A lot of virtual learning students probably frequent SL more often and hence get a hang of [those SL] skills. That will definitely make a huge difference in the flow of each task delivery. (blog post, $17 / 12 / 2016)$

This finding suggests the feasibility of conducting teacher training and supervision (typically done in a face-to-face classroom setting) in a virtual environment. That is, newbie teachers can also benefit from ongoing supervision and context-responsive strategies provided by the mentors/researchers in every step of the AR process through user-friendly digital platforms, such as blogs or Google Docs (Sato \& Chen, 2019).

\section{Conclusions and Implications}

Despite a steep learning curve, the trial-and-error process evidenced in the AR process had empowered Sabrina and crystalised her new understanding in task-based, 3D virtual teaching. Implications drawn from this AR-informed, narrative case study offer future directions for teacher educators to consider in language teaching in SL in order to mitigate unforeseen pitfalls:

1. It is vital to find a suitable SL location and test SL features to avoid student confusion as triggered by echo noise in a "cramped" vicinity (e.g., restaurant roleplay);

2. Students' different accents due to diverse cultural/linguistic backgrounds may cause communication breakdowns but also push for more task-based negotiations to resolve misunderstandings (e.g., object building);

3. 3D virtual teaching takes careful lesson planning, piloting and consultation with the expert (mentor) to ensure that a complex task can run more smoothly (e.g., maze 
exit);

4. Offering students L $\$$ to purchase more SL items (as opposed to freebies) optimises their immersive experience and task engagement (e.g., cultural outfits);

5. Students benefit from SL orientations and ongoing technical support and should acquaint themselves with SL functionality outside of class (e.g., debriefing).

These lessons learned by the SL newbie teacher provide best practices for teacher professional development, task design and student support in the 3D virtual environment. Furthermore, these valuable lessons demonstrate how AR research can yield more meaningful implications that respond to the context-specific needs of the practitioners (Burns, 2015, 2016), thereby supporting the positive claims made by prior AR research in the development of teacher agency and professional growth (Alwright \& Bailey, 1991; Goodnough, 2010; Yuan \& Burns, 2017).

Also noteworthy are Sabrina's ongoing critical reflections on her online teaching via blogging, co-constructed with the researcher in mentor-mentee dialoguing (Sato \& Chen, 2019). Virtual mentoring was hence established as the researcher would shadow her SL teaching through watching the recorded video clips (virtual class observation), providing feedback on her lesson delivery (debriefing) and responding to her blog posts and inquiries (supervising). This exercise suggests an ecological approach for online mentoring to support newbie teachers and highlight the primacy of AR in practitioner-researcher collaboration so that research-based, pedagogically-driven knowledge can be generated (Burns, 2015; Edwards \& Burns, 2016). Thus, she had ample opportunities to express her voice as a SL newbie teacher and receive personalised mentorship, thereby fostering her online teaching repertoire and teacher efficacy (Cheong, 2010; Rovegno \& Pintos, 2017). As Kozlova and Priven (2015) argue, teaching in 3D MUVEs could be “...difficult, time consuming, and practically impossible for novice teachers to explore the environment and to learn how to teach in such environment on their own" (p. 98). Future studies on teacher training in a fully online environment and how teacher beliefs and professional development evolve through practitioner research are desired (Burns, 2016; Rovegno \& Pintos, 2017).

Through her online teaching trajectory, her story also unfolds evidence-based, context-responsive dimensions (e.g., teaching strategies, critical reflections, SL immersion and task engagement) that underscore her resilience to overcome different challenges, and the empowerment of her online teacher identity in AR (Edwards \& Burns, 2016; Yuan \& Burns, 2017). When asked about any suggestions for future teaching in SL, Sabrina shared her final thought with other likeminded teachers:

Teaching in a virtual environment is challenging and stretching. Immerse yourself in the virtual world as much as possible before you meet students online. Your proficiency level will determine how effectively you can prepare students and respond to their issues. Read up about what others have done before you, reflect constantly on what worked and what didn't and persevere. Increased student engagement and motivation within a language learning context are worth the amount of effort required on the teacher's part (Sabrina, interview, 17/12/2016).

Indeed, technological, pedagogical, evaluative skills are developed concurrently rather than linearly in 3D MUVEs (Compton, 2009). Novice teachers continue revisiting and refining their skill set, which are shaping and shaped by new insights and reflections gained from their trial and error in teaching (Kozlova \& Priven, 2015) as evidenced in AR. This narrative case study transports us to Sabrina's debut online teaching and implicates that teaching English in SL, though challenging, could be as pedagogically motivating to students as professionally rewarding to teachers interested in embarking on this 3D virtual journey. For future research, it would be insightful to provide best practices for teacher professional development and online supervision - a third space that still deserves more research attention. 


\section{Acknowledgements}

This study was conducted under the auspices of the Teaching Excellence Development Fund (TEDF) at Curtin University. The author would also like to extend his gratitude to the teacher participant (S. Kent) for her commitment and support for this research grant project.

\section{Author Bio}

Julian C. Chen is a senior lecturer in the Applied Linguistics/TESOL Program at Curtin University. His research interests include technology-enhanced language learning, task-based language teaching, and action research. His work has appeared in high-impact, refereed journals, such as Computer-assisted Language Learning, Language Teaching Research, and The Modern Language Journal.

\section{References}

Allwright, D., \& Bailey, K. M. (1991). Focus on the language classroom: An introduction to classroom research for language teachers. Cambridge, UK: Cambridge University Press.

Banegas, D., Pavese, A., Velázquez, A., \& Vélez, S. M. (2013). Teacher professional development through collaborative action research: Impact on foreign Englishlanguage teaching and learning. Educational Action Research, 21(2), 185-201. https://doi.org/10.1080/09650792.2013.789717

Barkhuizen, G. (2015). Narrative inquiry. In B. Paltridge \& A. Phakiti (Eds.), Research methods in applied linguistics (2nd ed., pp. 169-185). London: Bloomsbury Academic.

Burns, A. (2015). Action research. In B. Paltridge \& A. Phakiti (Eds.), Research methods in applied linguistics: A practical resource (pp.187-204). London: Bloomsbury Publishing.

Burns, A. (2016). Practitioner research. In A. Mahboob, B. Paltridge, A. Phakiti, E. Wagner, S. Starfield, A. Burns, ... \& P. I. De Costa (Eds.), TESOL Quarterly research guidelines (pp. 56-59). TESOL Quarterly, 50(1), 42-65. http://dx.doi.org/10.1002/tesq.288

Canto, S., Jauregi, K., \& van den Bergh, H. (2013). Integrating cross-cultural interaction through video-communication and virtual worlds in foreign language teaching programs: Is there an added value? ReCALL, 25(1), 105-121. http://dx.doi.org/10.1017/S0958344012000274

Chen, J. C. (2016a). EFL learners' strategy use during task-based interaction in Second Life. Australasian Journal of Educational Technology, 32(3), 1-17. http://dx.doi.org/10.14742/ajet.2306

Chen, J. C. (2016b). The crossroads of English language learners, task-based instruction, and 3D multi-user virtual learning in Second Life. Computers \& Education, 102, 152-171. http://dx.doi.org/10.1016/j.compedu.2016.08.004

Chen, J. C. (2018). The interplay of tasks, strategies and negotiations in Second Life. Computer Assisted Language Learning, 31(8), 960-986. http://dx.doi.org/10.1080/09588221.2018.1466810

Cheong, D. (2010). The effects of practice teaching sessions in second life on the change in pre-service teachers' teaching efficacy. Computers \& Education, 55(2), 868-880. http://dx.doi.org/10.1016/j.compedu.2010.03.018

Compton, L. K. (2009). Preparing language teachers to teach language online: A look at skills, roles, and responsibilities. Computer Assisted Language Learning, 22(1), 73 99. http://dx.doi.org/10.1080/09588220802613831

Cornwell, S. (1999). Interview with Anne Burns and Graham Crookes. The Language 
Teacher, 23(12), 5-10.

Creswell, J. W. (2012). Educational research: Planning, conducting, and evaluating quantitative and qualitative research ( ${ }^{\text {th }}$ Ed.). Boston, MA: Pearson.

Dawley, L., \& Dede, C. (2014). Situated learning in virtual worlds and immersive simulations. In J. M. Spector, M. D. Merrill, J. Elen, \& M. J. Bishop (Eds.), The handbook of research on educational communications and technology (pp. 723-734). New York, NY: Springer. http://dx.doi.org/10.1007/978-1-4614-3185-5_58

Deutschmann, M., Panichi, L., \& Molka-Danielsen, J. (2009). Designing oral participation in Second Life-a comparative study of two language proficiency courses. ReCALL, 21(2), 206-226. http://dx.doi.org/10.1017/S0958344009000196

Deutschmann, M., \& Panichi, L. (2013). Towards models for designing language learning in virtual worlds. International Journal of Virtual and Personal Learning Environments (IJVPLE), 4(2), 65-84. http://dx.doi.org/10.4018/jvple.2013040104

Doughty, C. J., \& Long, M. (2003). Optimal psycholinguistic environments for distance Foreign language learning. Language Learning \& Technology, 7(3), 50-80.

Duff, P. (2012). How to carry out case study research. In A. Mackey \& S. M. Gass (Eds.), Research methods in second language acquisition: A practical guide (pp. 95-116). Oxford: Wiley-Blackwell. http://dx.doi.org/10.1002/9781444347340.ch6

Edwards, E., \& Burns, A. (2016). Language teacher-researcher identity negotiation: An ecological perspective. TESOL Quarterly, 50(3), 735-745. https://doi.org/10.1002/tesq.313

Ellis, R. (2009). Task-based language teaching: Sorting out the misunderstandings. International journal of applied linguistics, 19(3), 221-246. http://dx.doi.org/10.1111/j.1473-4192.2009.00231.x

Friedman, D. A. (2012). How to collect and analyze qualitative data. In A. Mackey \& S. M. Gass (Eds.), Research methods in second language acquisition: A practical guide (pp. 180-200). Oxford: Wiley-Blackwell. http://dx.doi.org/10.1002/9781444347340.ch10

González-Lloret, M., \& Ortega, L. (2014). Technology-mediated TBLT: Researching technology and tasks. Philadelphia, PA: John Benjamins. http://dx.doi.org/10.1075/tblt.6

Goodnough, K. (2010). The role of action research in transforming teacher identity: Modes of belonging and ecological perspectives. Educational Action Research, 18(2), 167-182. https://doi.org/10.1080/09650791003740725

Jauregi, K., Canto, S., De Graaff, R., Koenraad, T., \& Moonen, M. (2011). Verbal interaction in Second Life: towards a pedagogic framework for task design. Computer Assisted Language Learning, 24(1), 77-101. http://dx.doi.org/10.1080/09588221.2010.538699

Kemmis, S., \& McTaggart, R. (1988). The nature of action research: The action research planner. Geelong: Deakin University Press.

Kluge, S., \& Riley, L. (2008). Teaching in virtual worlds: Opportunities and challenges. Issues in Information Science and Information Technology, 5(1), 127-135.

Kozlova, I., \& Priven, D. (2015). ESL teacher training in 3D virtual worlds. Language Learning \& Technology, 19(1), 83-10

Lan, Y. J., Fang, S. Y., Legault, J., \& Li, P. (2015). Second language acquisition of Mandarin Chinese vocabulary: Context of learning effects. Educational Technology Research and Development, 63(5), 671-690. http://dx.doi.org/10.1007/s11423-015-9380-y

Liang, M. Y. (2012). Reimagining communicative context: ELF interaction in Second Life to learn EFL. Journal of Language, Identity \& Education, 11(1), 16-34. http://dx.doi.org/10.1080/15348458.2012.644118

Lin, T. J., Wang, S. Y., Grant, S., Chien, C. L., \& Lan, Y. J. (2014). Task-based teaching 
approaches of Chinese as a foreign language in Second Life through teachers' perspectives. Procedia Technology, 13, 16-22.

http://dx.doi.org/10.1016/j.protcy.2014.02.004

Long, M. H. (2016). In defense of tasks and TBLT: Nonissues and real issues. Annual Review of Applied Linguistics, 36, 5-33. http://dx.doi.org/10.1017/S0267190515000057

Merriam, S. B. \& Tisdell, E. J. (2016). Dealing with validity, reliability, and ethics. In Qualitative research: A guide to design and implementation ( $4^{\text {th }}$ ed., pp. 237-266). San Francisco, CA: Jossey-Bass.

Ortega, L., \& González-Lloret, M. (2015). Staking out the territory of technology-mediated TBLT. In M. Bygate (Ed.), Domains and directions in the development of TBLT: A decade of plenaries from the international conference (pp. 59-86). Amsterdam: John Benjamins Publishing Company. http://dx.doi.org/10.1075/tblt.8.03ort

Peterson, M. (2010). Learner participation patterns and strategy use in Second Life: an exploratory case study. ReCALL, 22(3), 273-292. http://dx.doi.org/10.1017/S0958344010000169

Peterson, M. (2012). EFL learner collaborative interaction in Second Life. ReCALL, 24(1), 20-39. http://dx.doi.org/10.1017/S0958344011000279

Peterson, M. (2016). Virtual worlds and language learning: An analysis of research. In F. Farr, \& L. Murrary (Eds.), The Routledge handbook of language learning and technology (pp. 308-319). New York, NY: Routledge.

Peterson, M., Wang, Q., \& Mirzaei, M. S. (2019). The use of network-based virtual world in second language education: A research review. In M. Kruk (ed.), Assessing the effectiveness of virtual technologies in foreign and second language instruction (pp. 1-25). Hershey, PA: IGI Global. http://dx.doi.org/10.4018/978-1-5225-7286-2.ch001

Rovegno, S. \& Pintos, V. (2017). Building up authentic knowledge through teacher research. In Banegas, D., et al. (Eds.), Authenticity in ELT: Selected Papers from the $42^{\text {nd }}$ FAAPI Conference (pp. 10-21). Posadas, Argentina: APIM.

Sadler, R. (2012). Virtual worlds for language learning: From theory to practice. Bern: Peter Lang.

Sato, E., \& Chen, J. C. (2019). Rise to the occasion: The trajectory of a novice Japanese teacher's first online teaching through action research. Language Teaching Research. Advance online publication, 1-24. https://doi.org/10.1177/1362168819846794

Sowa, P. A. (2009). Understanding our learners and developing reflective practice: Conducting action research with English language learners. Teaching and teacher education, 25(8), 1026-1032. https://doi.org/10.1016/j.tate.2009.04.008

Wehner, A. K., Gump, A. W., \& Downey, S. (2011). The effects of Second Life on the motivation of undergraduate students learning a foreign language. Computer Assisted Language Learning, 24(3), 277-289. http://dx.doi.org/10.1080/09588221.2010.551757

Yuan, R., \& Burns, A. (2017). Teacher identity development through action research: A Chinese experience. Teachers and Teaching, 23(6), 729-749. https://doi.org/10.1080/13540602.2016.1219713 


\section{Appendix. Semi-structured Interview Questions}

Thank you so much for allowing me to shadow you along the way. Your first virtual teaching experience as a newbie SL teacher is truly fascinating! I'd like to take the liberty of interviewing you here while your memory is still fresh:

- As a SL newbie teacher, what are your overall views about your first SL teaching vs. RL teaching?

- What did you enjoy the most about this SL class?

- What did you like the least about this SL class?

- Which SL features did you find useful for language teaching?

- What did you find challenging with SL features?

- What worked and didn't work for each weekly SL task (i.e., art gallery visit, role-play in a restaurant, object building, Maze, SL interview, runway show)?

- Given the proficiency level and characteristics of your student cohort, how did you find those tasks beneficial (or not) to language learning teaching?

- Based on your observation and personal experience, what role did "avatar" play in students' language practices and your teaching in SL?

- If you could teach this SL class again, what would you do differently this time?

- What are your final words for your fellow teachers who would like to embark on this SL teaching journey as a newbie? 